\title{
STUDY OF CLINICAL PROFILE OF TUBERCULOUS LYMPHADENITIS
}

\author{
Kshitij Dhull1, Kiran Somani², Rajesh Sharma3 ${ }^{3}$ Akhilesh Patel ${ }^{4}$, Rohan Chaphekar ${ }^{5}$, Rishikant Varhistha ${ }^{6}$
}

${ }_{1}^{1}$ Resident, Department of General Surgery, Sri Aurobindo Medical College and Postgraduate Institute, Indore, Madhya Pradesh, India. 2Professor, Department of General Surgery, Sri Aurobindo Medical College and Postgraduate Institute, Indore, Madhya Pradesh, India. 3 Professor and HOD, Department of General Surgery, Sri Aurobindo Medical College and Postgraduate Institute, Indore, Madhya Pradesh, India.

${ }^{4}$ Resident, Department of General Surgery, Sri Aurobindo Medical College and Postgraduate Institute, Indore, Madhya Pradesh, India. ${ }_{5}^{5}$ Assistant Professor, Department of General Surgery, Sri Aurobindo Medical College and Postgraduate Institute, Indore, Madhya Pradesh, India.

${ }^{6}$ Professor, Department of General Surgery, Sri Aurobindo Medical College and Postgraduate Institute, Indore, Madhya Pradesh, India. ABSTRACT

\section{BACKGROUND}

Tuberculous lymphadenitis is the commonest form of extra pulmonary tuberculosis and most commonly cervical lymph nodes are affected. A high index of suspicion is needed for diagnosis of tuberculous lymphadenitis which is known to mimic numerous pathological conditions. Availability of molecular technology has improved the ease of diagnosis. We wanted to study the clinical profile, diagnostic dilemmas and management of tubercular lymphadenitis

\section{METHODS}

This descriptive study was conducted in the Department of General surgery at Sri Aurobindo Medical College and Post Graduate Institute between September 2015 to February 2017. The work was started after the review \& approval of protocol of study by Institutional Ethics and Research committees. We included all patients with provisional diagnosis of tubercular lymphadenitis and 52 patients were made part of this study. A detail clinical history was taken. Thorough local \& systemic examination was done. After clinical diagnosis, further investigated to confirm the diagnosis. Appropriate treatment was instituted \& follow up done.

\section{RESULTS}

Total 52 Patients, 29 Female and 23 Male, in 20-60 years age group were included in study with a confirmed diagnosis of tubercular lymphadenitis. 39 (75\%) patients belonged to low socioeconomic status. 24 (46\%) patients presented to hospital between 1-3 months of symptoms. $36(69.2 \%)$ patients were diagnosed with tuberculosis for the first time (primary tuberculosis of lymph mode ) 17 (33\%) patients presented with constitutional symptoms like, fever, cough, loss of weight \& loss of appetite. 32 (63\%) patients had multiple nodes affected. 44 (85\%) patients had positive tuberculin test. FNAC was positive in 42 (81\%) cases CBNAAT was performed in 10 cases who were negative on FNAC. All cases with primary tuberculosis were started on DOTs CAT I \& patients who had previous history of tuberculosis were started on DOTs CAT II regimen.

\section{CONCLUSIONS}

Though anti-tuberculosis chemotherapy is the mainstay of treatment for tubercular lymphadenitis, surgical treatment is more useful in selected cases. In this regard, early diagnosis and treatment are critical in lowering the overall prevalence. Lymph node tuberculosis is different from pulmonary tuberculosis in terms of diagnosis \& management. With the availability molecular diagnosis, the diagnostic scenario has changed in the last decade, though treatment has not changed much since the last decade. Paradoxical reactions occur in $10-15 \%$ of immune-competent and approximately $50 \%$ of human immunodeficiency virus positive patients and need appropriate management. Every effort should be made to know the drug sensitivity of the organism at the onset of treatment by using molecular tests.

HOW TO CITE THIS ARTICLE: Dhull K, Somani K, Sharma R, et al. Study of clinical profile of tuberculous lymphadenitis. J. Evolution Med. Dent. Sci. 2019;8(13):1023-1026, DOI: 10.14260/jemds/2019/227

\section{BACKGROUND}

Tuberculosis has emerged as one of the most lethal diseases man has ever faced. India accounts for nearly one third of global burden of tuberculosis, it is a major health problem with sociological and economic causes. Tuberculosis which involves lungs usually can also cause infection in any other organ and tissue in the body.

'Financial or Other Competing Interest': None.

Submission 14-02-2019, Peer Review 20-03-2019,

Acceptance 26-03-2019, Published 01-04-2019.

Corresponding Author:

Dr. Kiran Somani,

\#205, Tirupati Apartment,

6, Gumashta Nagar, Indore-452009,

Madhya Pradesh, India.

E-mail: somanikiran@yahoo.com

DOI: $10.14260 /$ jemds $/ 2019 / 227$
Notable extra pulmonary sites include pleura, central nervous system, lymphatic system, genitourinary system and bone [Skeletal system]. Tuberculous lymphadenopathy is common in endemic area it accounts for 16 to $30 \%$ of all types of tuberculosis. In west there is resurgence among intravenous drug abusers and immunocompromised individuals with HIV positive status.[1] Around 2 to $3 \%$ of the patients attending general hospitals suffer from glandular tuberculosis, since the part is often exposed and leaves behind cosmetically an ugly scar as a hallmark of tuberculosis. Tuberculosis was the most common clinical condition affecting the cervical lymph nodes. [2] which may range from $60-90 \%$ [3] Various methods of treatment have been recommended from time to time ranging from royal touch to radiation, chemotherapeutic agents, antibiotics etc. 


\section{METHODS}

This descriptive study was conducted in the Department of General surgery at Sri Aurobindo Medical College and Post Graduate Institute for a period of one \& half year form September 2015 to February 2017. The work was started after the review \& approval of protocol of study by Institutional Ethics and Research committees. All the cases with provisional diagnosis of tuberculous cervical lymphadenitis getting treated in Sri Aurobindo Hospital during the period of study were included \& following patient were excluded from the study-

- Patients with cervical lymphadenitis due other diseases were excluded from the study.

- Patients with enlarged neck nodes of less than two weeks duration.

- $\quad$ Patients below 16 years of age.

- Patients who were not willing for study.

- Seropositive patients were excluded.

A total no. of 52 patients were made part of this study. Demographic data pertaining to subject was recorded A detail clinical history was taken \& local \& systemic examination done thoroughly. All patients were investigated for haematological, serological \& biochemical abnormalities. Other specific tests like FNAC, X- ray chest, ADA level, CBNAAT were done to conform the diagnosis. Then patient was given anti tuberculosis treatment as per latest RNTCP \& WHO guide lines. Follow-up of all these patients done for a period of 1 year. The collected data was entered on a master chart \& analysed by simple statistical methods.

\section{RESULTS}

\begin{tabular}{|c|c|c|}
\hline Age Group & Number & Percentage \\
\hline 16-20 years & 9 & 17.3 \\
\hline 21-30 years & 23 & 44.2 \\
\hline 31-40 years & 12 & 23.1 \\
\hline 41-50 years & 6 & 11.5 \\
\hline 51-60 years & 2 & 3.8 \\
\hline Total & $\mathbf{5 2}$ & $\mathbf{1 0 0 . 0}$ \\
\hline \multicolumn{2}{|c}{ Table 1. Distribution According to Age } \\
\hline
\end{tabular}

Majority of the patients in our study were of age group 21-30 years $23(44.2 \%)$, followed by $31-40$ years $12(23.1 \%)$, there were $9(17.3 \%)$ patients $<=20$ years, $6(11.5 \%)$ in the age group 41-50 years and 2 (3.8\%) in the age group 51-60 years.

\begin{tabular}{|c|c|c|}
\hline Gender & Number & Percentage \\
\hline Female & 29 & 55.8 \\
\hline Male & 23 & 44.2 \\
\hline Total & $\mathbf{5 2}$ & $\mathbf{1 0 0 . 0}$ \\
\hline Table 2. Distribution According to Gender \\
\hline
\end{tabular}

There was female preponderance with 29 (55.8\%) females and $23(44.2 \%)$ males in the present study.

\begin{tabular}{|c|c|c|}
\hline Socioeconomic Status & Number & Percentage \\
\hline Low & 39 & 75.0 \\
\hline Average & 13 & 25.0 \\
\hline High & 0 & 0.0 \\
\hline Total & $\mathbf{5 2}$ & $\mathbf{1 0 0 . 0}$ \\
\hline Table 3. Distribution According to Socioeconomic Status \\
\hline
\end{tabular}

Most of the patients $39(75.0 \%)$ were from low socioeconomic status, $13(25.0 \%)$ were from average socioeconomic status.

\begin{tabular}{|c|c|c|}
\hline Duration of Disease & Number & Percentage \\
\hline$<=1$ month & 17 & 32.7 \\
\hline 1-3 months & 24 & 46.2 \\
\hline 3-6 months & 5 & 9.6 \\
\hline$>6$ months & 6 & 11.5 \\
\hline Total & 52 & 100.0 \\
\hline
\end{tabular}

There were 17 (32.7\%) patients who presented within 1 month of neck swelling, $24(46.2 \%)$ had duration of disease between 1-3 months, 5 (9.6\%) had duration of disease between 3-6 months and $6(11.5 \%)$ presented after 6 months.

\begin{tabular}{|c|c|c|}
\hline Type of TB & Number & Percentage \\
\hline Primary & 36 & 69.2 \\
\hline Secondary & 16 & 30.8 \\
\hline Total & $\mathbf{5 2}$ & $\mathbf{1 0 0 . 0}$ \\
\hline \multicolumn{2}{|c|}{ Table 5. Distribution According to Type of TB } \\
\hline
\end{tabular}

Majority of patients had primary tuberculosis 36 (69.2\%) and $16(30.8 \%)$ were having secondary tuberculosis.

\begin{tabular}{|c|c|c|}
\hline Constitutional Symptoms & Number & Percentage \\
\hline Absent & 35 & 67.3 \\
\hline Present & 17 & 32.7 \\
\hline Total & $\mathbf{5 2}$ & $\mathbf{1 0 0 . 0}$ \\
\hline \multicolumn{2}{|c|}{ Table 6. Distribution According to Constitutional } \\
Symptoms \\
\hline
\end{tabular}

Most of the patients 35 (67.3\%) patients did not have any constitutional symptoms, while $17(32.7 \%)$ patients had constitutional symptoms like fever, cough, loss of weight and appetite.

\begin{tabular}{|c|c|c|}
\hline Clinical Presentation & Number & Percentage \\
\hline Lymphadenitis & 6 & 11.5 \\
\hline Peri-Adenitis & 24 & 46.1 \\
\hline Cold Abscess & 11 & 21.2 \\
\hline Collar Stud Abscess & 7 & 13.4 \\
\hline Sinus & 5 & 9.6 \\
\hline
\end{tabular}

There were 6 (11.5\%) patients who had lymphadenitis, $24(46.1 \%)$ patients had peri-adenitis, $11(21.2 \%)$ had cold abscess, 7 (13.4\%) had collar stud abscess while 5 (9.6\%) had sinus on presentation to hospital.

\begin{tabular}{|c|c|c|}
\hline Other LN Groups & Number & Percentage \\
\hline Only Cervical LN Involvement & 46 & 88.5 \\
\hline Axillary + Cervical & 4 & 7.7 \\
\hline Inguinal + Cervical & 1 & 1.9 \\
\hline Para-Aortic + Cervical & 1 & 1.9 \\
\hline Total & 52 & 100.0 \\
\hline
\end{tabular}

Majority of the patients 46 (88.5\%) had only cervical LN involvement, while $4(7.7 \%)$ had axillary + cervical lymph nodes involvement, $1(1.9 \%)$ had inguinal + cervical lymph nodes involvement, $1(1.9 \%)$ had para-aortic + cervical lymph node involvement. 


\begin{tabular}{|c|c|c|}
\hline Mantoux Test Results & Number & Percentage \\
\hline Negative & 8 & 15.4 \\
\hline Positive & 44 & 84.6 \\
\hline Total & $\mathbf{5 2}$ & $\mathbf{1 0 0 . 0}$ \\
\hline \multicolumn{2}{|c|}{ Table 9. Distribution According to Mantoux Test Results } \\
\hline
\end{tabular}

Majority of the patients $44(84.6 \%)$ Mantoux test was positive, while in $8(15.4 \%)$ patients Mantoux test was negative.

\begin{tabular}{|c|c|c|}
\hline FNAC & Number & Percentage \\
\hline Negative & 6 & 11.5 \\
\hline Doubtful & 4 & 7.7 \\
\hline Positive & 42 & 80.8 \\
\hline Total & $\mathbf{5 2}$ & $\mathbf{1 0 0 . 0}$ \\
\hline Table 10. Distribution According to FNAC \\
\hline
\end{tabular}

In $6(11.5 \%)$ patients FNAC was negative, it was doubtful in $4(7.7 \%)$ patients and in majority of the patients 42 (80.8\%) FNAC was positive.

\begin{tabular}{|c|c|c|}
\hline CBNAAT & Number & Percentage \\
\hline Performed and Positive & 10 & 100.0 \\
\hline Total & 10 & 100.0 \\
\hline \multicolumn{3}{|c|}{ Table 11. Distribution According to CBNAAT } \\
\hline
\end{tabular}

Of the 52 patients included in the study, CBNAAT was performed in only 10 cases, who were negative or doubt full on FNAC.

All these cases were positive for CBNAAT (100\%).

\begin{tabular}{|c|c|c|}
\hline Chest X-ray & Number & Percentage \\
\hline Negative for P.TB. & 35 & 67.3 \\
\hline Positive & 17 & 32.7 \\
\hline Total & $\mathbf{5 2}$ & $\mathbf{1 0 0 . 0}$ \\
\hline Table 12. Distribution According to Chest X-ray \\
\hline
\end{tabular}

In 35 (67.3\%) patients, chest $\mathrm{x}$-ray did not show any signs for pulmonary tuberculosis, while it was positive in 17 (32.7\%) patients.

\begin{tabular}{|c|c|c|}
\hline ADA/ESR & Number & Percentage \\
\hline$>30 \mathrm{ADA}$ & 51 & 98.1 \\
\hline >19 ESR & 41 & 78.8 \\
\hline \multicolumn{2}{|c|}{$\begin{array}{c}\text { Table 13. Distribution According to ADA and ESR Cut Off } \\
\text { Value }\end{array}$} \\
\hline
\end{tabular}

$51(98.1 \%)$ patients had ADA level >30, and $41(78.8 \%)$ had ESR > 19 .

\begin{tabular}{|c|c|c|}
\hline & Number & Percentage \\
\hline Excision Biopsy & 14 & 26.6 \\
\hline Anti-Gravity Aspiration & 13 & 25.0 \\
\hline Drainage / Curettage & 10 & 19.2 \\
\hline Managed Conservatively & 15 & 28.2 \\
\hline \multicolumn{3}{|c|}{$\begin{array}{l}\text { Table 14. Distribution According to Surgical Procedure } \\
\text { Performed }\end{array}$} \\
\hline
\end{tabular}

Excision biopsy was performed in ten cases negative or doubt full on FNAC and was positive in all. Excision biopsy was also performed for cosmetic reasons in four cases already proven by FNAC.
Anti-Gravity aspiration was done for cases with cold abscess and collar stud abscess.

Drainage/Curettage was done for cases with collar stud abscess and sinus formation.

\begin{tabular}{|c|c|c|}
\hline Treatment & Number & Percentage \\
\hline Category-I & 36 & 69.2 \\
\hline Category-II & 16 & 30.8 \\
\hline Total & $\mathbf{5 2}$ & $\mathbf{1 0 0 . 0}$ \\
\hline Table 15. Distribution According to Treatment \\
\hline
\end{tabular}

Majority of the patients $36(69.2 \%)$ patients had taken Category-I treatment while 16 (30.8\%) took Category-II treatment.

\section{DISCUSSION}

Tuberculous lymphadenitis is considered a local manifestation of the systemic disease, whereas lymphadenitis due to nontuberculous mycobacteria is truly a localized disease.[4] Tuberculous lymphadenitis may occur due to reactivation of healed focus involved during primary infection. And source of infection may be from Tonsils: In majority of instances, tubercle bacilli gains entrance through tonsils of the corresponding side (Bailey). But in those situations when the lesion has healed, or the lesion will be so minimal that its identification becomes impossible. Tonsil can be tubercular without glandular involvement.[5] Tooth: Sometimes tubercle bacilli can be demonstrated in various tooth and it should be suspected when submandibular or submental groups of lymph nodes are principally affected.[6] Path of infection: Source of infection is from patients with open type of tuberculosis and carriers. Port of entry: ${ }^{[7]}$ The bacillus is filtered in nostrils and adenoids and it produces a lesion in the draining lymph nodes. The bacilli are carried by droplet infection. Droplet infection: With the process of coughing and sneezing, droplets containing bacilli can be ejected right onto the face, thus can easily take up their place in host without losing much of its vitality. They begin to lose their vitality outside human body. "Tuberculous carriers may possess thousands of bacilli in throat and nasal passages which are ejected in the process of coughing in the neighbourhood of susceptible persons. Dust infection: Bacilli laden sputum when spit out to the open public street which is dried, pulverised, and it is carried as dust before the bacilli can enter the system of inhalation, but its importance is only secondary to the droplet infection, because the bacilli in dust is more often persist. Tubercle bacilli however can remain alive for 3 months in darkness screen and in protected corners (Frimodt muller). If the lymphadenitis is haematogenous in origin, there may be multiple groups involved including axilla. Cervical nodes are the most commonly affected nodes in tuberculous lymphadenitis, accounting for approximately $63 \%$ of cases, followed by mediastinal $(27 \%)$ and axillary nodes (8\%), mesenteric hepatic, portal, perihepatic and inguinal lymph node.[8-9]

The clinical manifestation of TB lymphadenitis largely depends upon the anatomical location of the affected nodes and immune status of the individual.[10-13]

Cervical lymphadenopathy is the most common manifestation of tuberculous lymphadenitis. Most frequently, a unilateral mass appears in the anterior or posterior cervical triangles; submandibular and supraclavicular lymph node 
involvement also occurs. Bilateral disease is uncommon. Although most patients have disease at only one site, multiple nodes may be involved at that site. Cervical lymphadenopathy may sometimes be associated with a simultaneous involvement of other nodes in the region, which may produce a variety of signs and symptoms depending upon the anatomical location of the affected nodes.

Jones and Campbell in 1962 described stages of TB lymphadenitis as follows

1. Enlarged, firm, mobile, discrete nodes.

2. Large rubbery nodes fixed to surrounding tissue.

3. Central softening abscess.

4. Collar stud formation.

5. Sinus tract formation.

The differential diagnosis of isolated peripheral lymphadenopathy is extensive and includes malignancy (e.g., Hodgkin lymphoma and non-Hodgkin lymphoma), infections (e.g., nontuberculous Mycobacteria (M. scrofulaceum, M. avium complex, M. kansasii), reactive hyperplasia, cat scratch disease, fungal infection, toxoplasma lymphadenitis, sarcoidosis, berylliosis, bacterial adenitis, and Kikuchi disease (idiopathic histiocytic necrotizing lymphadenitis).

Diagnosis of tuberculous lymphadenitis is established by histopathology examination along with acid-fast bacilli (AFB) smear and AFB culture of lymph node material obtained by FNAC, Excision biopsy.

\section{CONCLUSIONS}

Lymph node tuberculosis is the most common form of extra pulmonary TB, is different from pulmonary TB in terms of diagnosis and management. Though anti-tuberculosis chemotherapy is the mainstay of treatment for tubercular lymphadenitis, surgical treatment is more useful in selected cases. In this regard, early diagnosis and treatment are critical in lowering the overall prevalence with the availability molecular diagnosis, the diagnostic scenario has changed in the last decade, though treatment has not changed much since the last decade. Paradoxical reactions occur in $10-15 \%$ of immune-competent and approximately $50 \%$ of human immunodeficiency virus positive patients and need appropriate management. Every effort should be made to know the drug sensitivity of the organism at the onset of treatment by using molecular tests.

\section{REFERENCES}

[1] Dandapat MC, Mishra BM, Dash SP, et al. Peripheral lymph node tuberculosis: a review of 80 cases. $\mathrm{Br} \mathrm{J}$ Surg 1990;77(8):911-2.

[2] Sharma SK, Mohan A. Extrapulmonary tuberculosis. Indian J Med Res 2004;120(4):316-53.

[3] Mohapatra PR, Janmeja AK. Tuberculous lymphadenitis. J Assoc physicians India 2009:57(6):585-90.

[4] Mathema B, Kurepina NE, Bifani PJ, et al. Molecular epidemiology of tuberculosis: current insights. Clin Microbiol Rev 2006;19(4):658-85.

[5] Norman SW, Christopher JK, O'Connel BPR. Bailey and Love's short practice of surgery. $25^{\text {th }}$ edn. London: Hodder Arnold Ltd., 2008: p. 731-2.

[6] Butt T, Riffat AN, Syed KY, et al. An update on the diagnosis of tuberculosis. JCPSP 2003;13(12):728-34.

[7] Iseman MD. Tuberculosis down through centuries. Chap - 1. In: A clinical guide to tuberculosis: India. Lippincott Williams and Wilkins 2000: p. 2, 4, 7, 14-17, 51-53.

[8] Thompson MM, Underwood MJ, Sayers RD, et al. Peripheral tuberculous lymphadenopathy: a review of 67 cases. Br J Surg 1992;79(8):763-4.

[9] Brizi MG, Celi G, Scaldazza AV, et al. Diagnostic imaging of abdominal tuberculosis: gastrointestinal tract, peritoneum, lymph nodes. Rays 1998;23(1):115-25.

[10] Alvarez S, McCabe WR. Extrapulmonary tuberculosis revisited: a review of experience at Boston City and other hospitals. Medicine (Baltimore) 1984;63(1):25-55.

[11] Shafer RW, Kim DS, Weiss JP, et al. Extrapulmonary tuberculosis in patients with human immunodeficiency virus infection. Medicine (Baltimore) 1991;70(6):384-97.

[12] Castro DJ, Hoover L, Castro DJ, et al. Cervical mycobacterial lymphadenitis. Medical vs surgical management. Arch Otolaryngol 1985;111(12):816-9.

[13] Artenstein AW, Kim JH, Williams WJ, et al. Isolated peripheral tuberculous lymphadenitis in adults: current clinical and diagnostic issues. Clin Infect Dis 1995;20(4):876-82. 